units, which usually have an annual turnover of over 50000 patients, should be run by a consultant in charge. As part of a training programme the career posts of registrar and senior house officer must be retained and if one takes an arbitrary figure of one doctor per 10000 patients a department such as this one, which sees 75000 patients a year, could best be staffed by having one consultant, two registrars, three full-time career-grade clinical assistants (or for want of a better though more out-ofdate description, medical assistants), as well as four senior house officers. This would allow a flexibility of staffing and enable a rota to be formed to cover the department at all times with both full-time career staff and training grades.

From past discussions with Department of Health and Social Security representatives I get the impression that it is the opinion of the Department that accident and emergency departments of the country should be staffed with full-time permanent staff; surely, therefore, the time is now ripe for a structure of medical staffing of these departments to be arranged and the future of departments throughout the country be guaranteed.

Accident and Emergency

JOHN K GosNOLD

Department,
Hull Royal Infirmary,
Hull, Humberside

\section{Time and money}

SIR,-Among the many abbreviations which abound in our everyday affairs, two in particular have of late assumed major prominence: UMTs and NHDs.

The preoccupation of our employing authorities with the measurement of elapsed time is, to my mind, a matter for grave concern. It would seem to stem from the fact that it is our misfortune to be subject to a Government in whose eyes earning capacity can be equated only with physical activity of the pick-andshovel variety or with the manipulative skills of the worker on a factory production line. In these, of course, the number of wheelbarrows filled or the number of bolts inserted and nuts tightened is directly related to the time spent on the job.

The practice of medicine in all its aspects differs rather significantly from activities of this sort in that as a profession which used to be regarded are learned we are paid for the application of specialised knowledge, and the time involved in doing so is largely irrelevant. My own position as a histopathologist is of particular interest. In the light of the current attitude of officialdom one can only deduce that when I am presented with a section of a typical breast carcinoma, the recognition of which involves no measurable lapse of time, it must follow that I cannot be regarded as having done any measurable work entitling me to remuneration. On the other hand when I encounter some obscure and atypical lesion necessitating recourse to various reference texts, a visit to the library, and a search of my files, having expended a substantial period of time on this, I can thus be considered to have earned my salary. Is there therefore more merit is not knowing the answer? Bear in mind, too, that should I encounter a further example of this lesion my recognition of it will then be immediate.

I do not earn my salary by the fact of being physically present in my office between certain

arbitrarily specified hours but by the application of my knowledge and experience to the diagnostic problems presented to me. The number of these items is something over which I have no control and is wholly dependent on the work done by other colleagues-which is determined by the number of patients referred to them by outside practitioners and this in turn arises from the random incidence of disease throughout the population. And yet we find ourselves subject to exhortations to "increased productivity" from our administrators-even from those medically qualified. How does one make these people understand that the practice of medicine has nothing in common with the manufacture of screw nails Granted there are many fields of medicine in which manual dexterity of the highest order is involved-but this is still applied in the ligh of prior specialised knowledge and it is by virtue of this, and not of time spent, that the doctor's salary is earned. With increasing experience, a surgeon may, for example, carry out a gastrectomy in half an hour less time than he could 10 years earlier. Is he thereby deemed to have earned less?

Oddly enough the application of specialised knowledge is recognised in the case of the skilled tradesman, as in the slightly apocryphal story of the garage bill:

\section{To hitting motor with hammer .. $5 \mathrm{p}$ To knowing where to hit it $£ 5$.}

But then, of course, the mechanic is still a member of the "working class" and we are not.

South Shields

\section{M MCCLURE}

\section{Dental dispute}

SIR,-May I comment briefly on Mr Ennals's statement about his dispute with the dental profession (3 December, $p$ 1487)? The Secretary of State gives the impression, rather skilfully, that dentists are rejecting a reasonable offer. In fact his "offer" remains as it was when the dispute first arose in July-that general dental practitioners must at some time or other repay any money accidentally "overpaid" during the years 1974-5 to 1976-7. We will not know the precise sum involved for some time; but whatever the size of the error it was the result of forecasting difficulties in a period of great economic uncertainty and the Department of Health was partly responsible. Mr Ennals says that overpayments can no more be ignored than underpayments. In fact the only confirmed overpayment is of $£ 299$ in 1974-5, which is more than balanced by an uncorrected (or ignored) underpayment of $£ 467$ in $1972-3$.

For three years of its post-Pilkington life the dental pay system incorporated retrospective adjustments of the fee scale's practice expense allowance. These adjustments were introduced by Barbara Castle in 1974 as part of a deliberate attempt to restore dentists confidence in their pay machinery. In the event the system proved extremely inefficient and we now want to dispense with it-having already wiped the slate clean last year by repaying the initial benefits. $\mathrm{Mr}$ Ennals has the same broad problem now as Mrs Castle had in 1974, with a dental fee scale so depressed and distorted by the effects of pay policy that the NHS general dental service is on the verge of collapse. When the Review Body has demonstrated so conclusively the underpay- ment of doctors and dentists is it reasonable of Mr Ennals to expect dentists to agree that at the same time they were being overpaid? His predecessor had a better understanding of the problem.

R A Followell Chairman General Dental Services Committee, British Dental Association

London W1

\section{Registration of overseas doctors}

SIR,-By December 19761500 persons had taken the TRAB examination, of whom 1000 had failed and 500 had passed, while 913 had been exempted. Such a large number of exemptions calls into question the validity of the procedure. Using the same pass rate as for those who took the test, I presume that some 600 of those exempted would probably have failed. I am convinced, too, that there is a serious fault with the clinical assessment part of TRAB because of the discrepancy between the $30 \%$ pass rate for the written section and the high pass rate in the clinical. The Department of Health and Social Security's blurb states: "It is a cause for pride that so few fail the clinical assessment." But surely a properly conducted clinical should have at least an equal and predictable proportion of failures as the written examination. The lack of congruency between the written and the practical parts of the test is astonishing. Indeed, the results would seem to be upside down.

Having had the chance to meet and talk with a few consultant assessors about their work, I found their comments revealing. One doctor, when asked how many he failed, said, "None. You can't send them home." A gynaecologist, asked about the assessment of the candidates' ability to examine a chest, replied, "If they want that they must send them to a physician." Another examiner confined his assessment to the area between the umbilicus and the pubes.

I know of several instances in which successful candidates' basic knowledge of science and medicine seemed below the standard required of university graduates here. One doctor, assisting at an amputation, was unable to name the nerves entering the leg. Another did not know what specific gravity or specific heat meant and could not explain isotonic fluids. According to another air contained $80 \%$ oxygen and expired air none at all. I presume that such gaps in basic knowledge would not prevent a doctor from taking higher qualifications, and what examiner at this level would think to test such facts?

It may seem invidious to pick such anecdotal examples from both sides of the assessment table, but I think they are sufficiently serious to demonstrate a weakness in our registration system. How many doctors know that temporary registration is no bar to a consultant appointment, though it does disqualify a candidate for general practice? Thus so far as the hospital service is concerned the distinction between temporary and permanent registration seems to have little value. Surely the time has come for reassessment of the whole procedure of registration.

Lowestoft, Suffolk

J P N Hicks

SIR,-Racial discrimination has been an emotive subject for a long time and one that 